\title{
Properties of Formation Mechanism of the Hydrothermally-Synthesized $\mathrm{ZrW}_{2} \mathrm{O}_{8}$
}

\author{
Elena S. Dedova ${ }^{1,2,3, a)}$, Sergei N. Kulkov ${ }^{1,2,3, b)}$, and Fernando Pedrasa ${ }^{4, c)}$ \\ ${ }^{1}$ Institute of Strength Physics and Materials Science SB RAS, Tomsk, 634055, Russia \\ ${ }^{2}$ National Research Tomsk State University, Tomsk, 634050, Russia \\ ${ }^{3}$ National Research Tomsk Polytechnic University, Tomsk, 634050, Russia \\ ${ }^{4}$ 223, avenue Albert Einstein, La Rochelle, 170071, France \\ a) Corresponding author: 1sdedova@yandex.ru \\ b) kulkov@ms.tsc.ru \\ c) vp-ri@univ-lr.fr
}

\begin{abstract}
A single-phase $\mathrm{ZrW}_{2} \mathrm{O}_{8}$ was prepared using the hydrothermal synthesis by decomposition of $\mathrm{ZrW}_{2} \mathrm{O}_{7}\left(\mathrm{OH}_{1.5}, \mathrm{Cl}_{0.5}\right) 2 \mathrm{H}_{2} \mathrm{O}$. The formation mechanism of $\mathrm{ZrW}_{2} \mathrm{O}_{8}$ was described. The morphology of the material was represented as elongated particles with an intrinsic block structure. The stability fields of $\mathrm{ZrW}_{2} \mathrm{O}_{8}$ were determined. The $\mathrm{ZrW}_{2} \mathrm{O}_{8}$ demonstrated a negative thermal expansion behavior in the temperature range from $25^{\circ} \mathrm{C}$ to $750^{\circ} \mathrm{C}$. Introduction of $\mathrm{ZrW}_{2} \mathrm{O}_{8}$ particles as reinforcement element into a metal matrix can lead to the formation of an internal stress caused by the difference between values of thermal expansion of matrix and reinforcing additives, which improve its mechanical properties.
\end{abstract}

Keywords: zirconium tungstate; hydrothermal synthesis; negative thermal expansion coefficient

\section{INTRODUCTION}

The development of new materials that exhibit unusual properties is one of the most rapidly developing areas of modern materials science. There are the materials characterized by negative thermal expansion (NTE) and that contract upon heating. Usually, the contraction is moderate and anisotropic, and it appears in a narrow temperature range only. $\mathrm{ZrW}_{2} \mathrm{O}_{8}$ is a perspective material due to its isotropic NTE $\left(\alpha=-9 \times 10^{-6 \circ} \mathrm{C}^{-1}\right.$ in the temperatures range from $-273^{\circ} \mathrm{C}$ to $770^{\circ} \mathrm{C}$ ) [1]. Zirconium tungstate can be very useful in the technology of composites. The practical use of the composites containing $\mathrm{ZrW}_{2} \mathrm{O}_{8}$ implies continuous operation under various conditions, including severe temperatures. On this basis, it is necessary to study the temperature behavior of $\mathrm{ZrW}_{2} \mathrm{O}_{8}$. Thermal analysis and in situ high-temperature X-ray studies will provide important information on the structural and phase transformations occurring in the process of material heating and reveal the mechanism of hydrothermally-produced $\mathrm{ZrW}_{2} \mathrm{O}_{8}$.

\section{MATERIALS AND EXPERIMENTAL PROCEDURE}

The following substances were used as source components for the production of a precursor: $\mathrm{Na}_{2} \mathrm{WO}_{4} \cdot 2 \mathrm{H}_{2} \mathrm{O}(\mathrm{AR}$ grade), $\mathrm{ZrOCl}_{2} \cdot 8 \mathrm{H}_{2} \mathrm{O}\left(\mathrm{CP}\right.$ grade) and $\mathrm{HCl}\left(\mathrm{CP}\right.$ grade). Aqueous solutions of $\mathrm{Na}_{2} \mathrm{WO}_{4} \cdot 2 \mathrm{H}_{2} \mathrm{O}(0.5 \mathrm{~mol} / \mathrm{L})$, $\mathrm{ZrOCl}_{2} \cdot 8 \mathrm{H}_{2} \mathrm{O}(0.25 \mathrm{~mol} / \mathrm{L}), \mathrm{HCl}(8 \mathrm{~mol} / \mathrm{L})$ were thoroughly mixed and placed into a Teflon-lined stainless steel autoclave. The hydrothermal reaction was conducted at $160^{\circ} \mathrm{C}$ for 36 hours. The product was repeatedly rinsed with distilled water and dried at $110^{\circ} \mathrm{C}$. High-temperature in situ XRD analyses of the powder were conducted using Bruker D8 diffractometer with $\mathrm{CuK}_{\alpha}$ source of filtered radiation at the Boreskov Institute of Catalysis of SB RAS. The analyses of particle form and size were conducted using JEM-2100 transmission electron microscope (TEM) and Phillips SEM 515 scanning electron microscopy (SEM). The commercially pure aluminum (ASD 6) was mixed

(C) 2014 AIP Publishing LLC 978-0-7354-1260-6/\$30.00 
with the obtained $\mathrm{ZrW}_{2} \mathrm{O}_{8}$ powder at various ratios $(0.1,0.5,1,5$ and $10 \mathrm{wt} . \%)$. The powder mixture was compacted and sintered at $600^{\circ} \mathrm{C}$ for 1 hour. The testing of Vickers hardness was conducted using PMT-3 harness gauge. Axial compression testing was performed using Instron 1185 device with the loading speed of $0.2 \mathrm{~mm} / \mathrm{s}$.

\section{RESULTS AND DISCUSSION \\ Formation Mechanism of $\mathrm{ZrW}_{2} \mathrm{O}_{8}$}

The initial powder of hydrothermally-synthesized $\mathrm{ZrW}_{2} \mathrm{O}_{7}(\mathrm{OH}, \mathrm{Cl})_{2} \cdot 2 \mathrm{H}_{2} \mathrm{O}$ precursor included two kinds of particles: agglomerates consisting of elongated filamentary particles $(\langle d\rangle=0.6 \mathrm{~nm})$ and individual elongated particles. The distribution of elongated particles by size (longitudinal and lateral) had a unimodal nature. With increasing temperature from $25^{\circ} \mathrm{C}$ to $350^{\circ} \mathrm{C}$ the average longitudinal size of the elongated particles varied from $2 \mathrm{~nm}$ to $1 \mu \mathrm{m}$. The average lateral size of the elongated particles was $0.2 \mu \mathrm{m}$. The calculation showed that the activation energy of particles was $8 \mathrm{~kJ} / \mathrm{mol}$ in the temperature range from $25^{\circ} \mathrm{C}$ to $350^{\circ} \mathrm{C}$, while in the range from $350^{\circ} \mathrm{C}$ to $600^{\circ} \mathrm{C}$ it was equal to $1 \mathrm{~kJ} / \mathrm{mol}$ (Fig. 1). The abrupt change of the activation energy for the temperature ranging from $200^{\circ} \mathrm{C}$ to $300^{\circ} \mathrm{C}$ evidences either the changes in the crystal lattice or the occurrence of a phase transition.

In situ XRD studies were used to investigate the mechanism of $\mathrm{ZrW}_{2} \mathrm{O}_{8}$ formation. At temperatures under $200^{\circ} \mathrm{C}$ only $\mathrm{ZrW}_{2} \mathrm{O}_{7}(\mathrm{OH}, \mathrm{Cl})_{2} \cdot 2 \mathrm{H}_{2} \mathrm{O}$ peaks were observed [2]. XRD patterns at the temperature of up to $500^{\circ} \mathrm{C}$ showed that the entire material went over to X-ray amorphous state. A further increase of the temperature up to $600^{\circ} \mathrm{C}$ lead to the formation of a crystalline structure that can be identified as cubic zirconium tungstate. The lattice parameter of the resulting cubic modification at $600^{\circ} \mathrm{C}$ is equal to $9.1211 \AA$, which agrees well with the literature data $(9.1540 \AA)$ [1]. For $700^{\circ} \mathrm{C}$ along with $\mathrm{ZrW}_{2} \mathrm{O}_{8}$ diffraction peaks there are those of $\mathrm{WO}_{3}$. The further increase of the temperature to $1000^{\circ} \mathrm{C}$ lead to the decomposition of $\mathrm{ZrW}_{2} \mathrm{O}_{8}$ into $\mathrm{WO}_{3}$ and $\mathrm{ZrO}_{2}$. Figure 2 demonstrates the dependence of the ratio of integral intensity of all X-ray reflexes to the background intensity $\left(\Sigma I / I_{\mathrm{b}}\right)$ on the temperature. This dependence was linearly approximated. There is an intersection point at $365^{\circ} \mathrm{C}$. The decrease of $\Sigma I / I_{\mathrm{b}}$ down to $400^{\circ} \mathrm{C}$ witnesses an amorphization and the further increase of the temperature is due to the material crystallization. Probably, the formation of $\mathrm{ZrW}_{2} \mathrm{O}_{8}$ occurs through the X-ray amorphous phase, which can be interpreted as a meso-nano transformation.

The formation of hydrothermally-synthesized $\mathrm{ZrW}_{2} \mathrm{O}_{8}$ proceeds in two stages: 1) transition of the crystalline $\mathrm{ZrW}_{2} \mathrm{O}_{7}(\mathrm{OH}, \mathrm{Cl})_{2} \cdot 2 \mathrm{H}_{2} \mathrm{O}$ precursor into the X-ray amorphous state with the activation energy of $8 \mathrm{~kJ} / \mathrm{mol} ; 2$ ) nucleation of $\mathrm{ZrW}_{2} \mathrm{O}_{8}$ at $350 \pm 25^{\circ} \mathrm{C}$ and the growth of nuclei up to the temperature reaching $550^{\circ} \mathrm{C}(Q=1 \mathrm{~kJ} / \mathrm{mol})$.

\section{Properties of $\mathrm{ZrW}_{2} \mathrm{O}_{8}$}

Observations of the morphology of zirconium tungstate using a transmission electron microscopy showed that $\mathrm{ZrW}_{2} \mathrm{O}_{8}$ powder consisted of elongated particles with an intrinsic block structure.

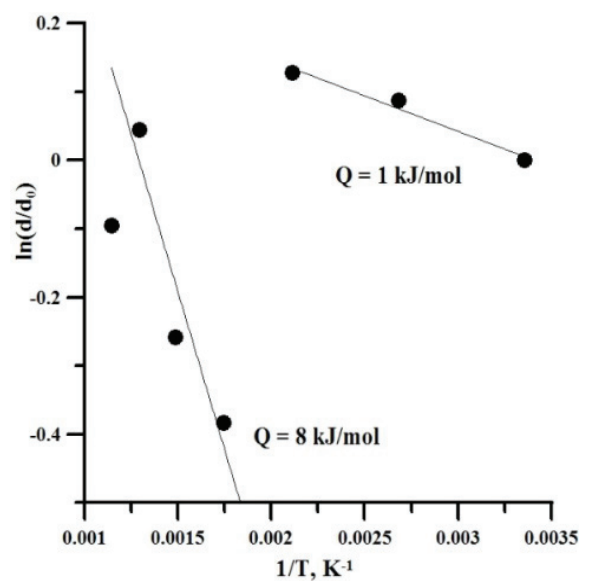

FIGURE 1. Dependence of particle size change of $\mathrm{ZrW}_{2} \mathrm{O}_{7}\left(\mathrm{OH}_{1,5} \mathrm{Cl}_{0,5}\right) \cdot 2 \mathrm{H}_{2} \mathrm{O}$ on temperature

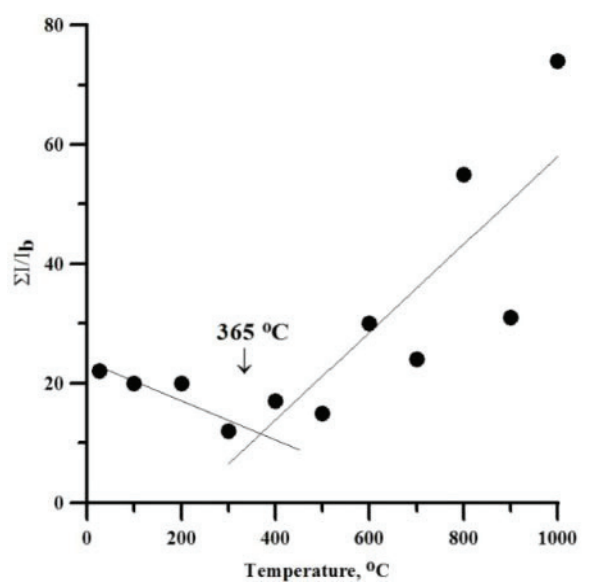

FIGURE 2. Dependence of ratio of total intensity of all X-ray reflexes to background intensity on temperature 


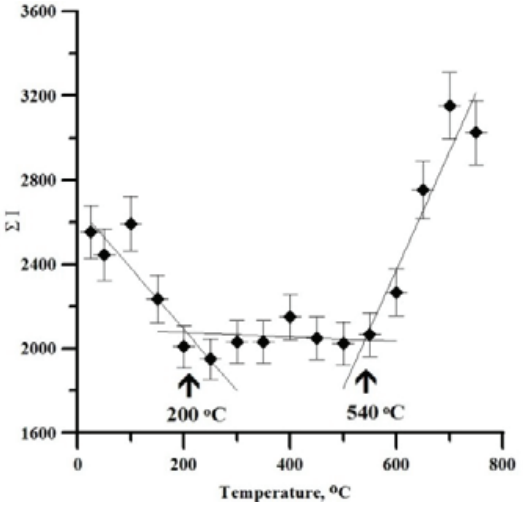

FIGURE 3. Dependence of total intensity $(\Sigma I)$ of all X-ray reflexes on temperature

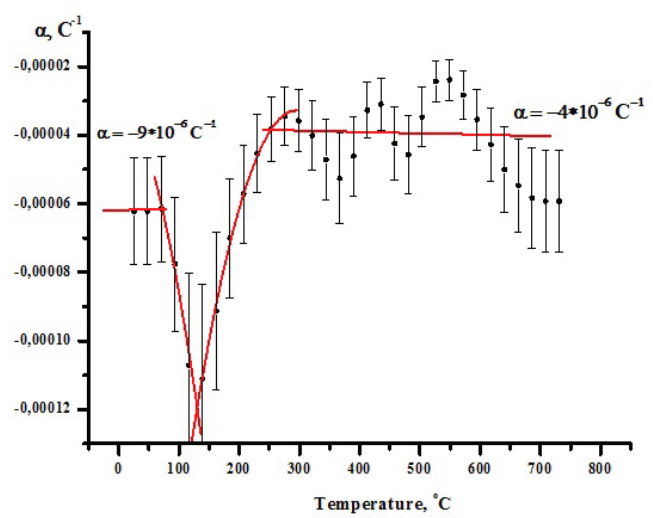

FIGURE 4. Dependence of coefficient of $\mathrm{ZrW}_{2} \mathrm{O}_{8}$ thermal expansion on temperature

The average block size varied from $20 \mathrm{~nm}$ to $50 \mathrm{~nm}$. The average lateral size of the elongated particles varied from $30 \mathrm{~nm}$ to $700 \mathrm{~nm}$, and the average longitudinal size varied from $0.5 \mu \mathrm{m}$ to $5.0 \mu \mathrm{m}$. The developed $\mathrm{ZrW}_{2} \mathrm{O}_{8}$ crystals inherit the shape and the size of $\mathrm{ZrW}_{2} \mathrm{O}_{7}\left(\mathrm{OH}_{1.5} \mathrm{Cl}_{0.5}\right) \cdot 2 \mathrm{H}_{2} \mathrm{O}$ crystals.

The results of high-temperature in situ XRD observations of $\mathrm{ZrW}_{2} \mathrm{O}_{8}$ showed a gradual decrease of the intensity of reflexes from surfaces $\left(\begin{array}{lll}1 & 1 & 1\end{array}\right),\left(\begin{array}{lll}2 & 2 & 1\end{array}\right)$ and $\left(\begin{array}{lll}3 & 1 & 0\end{array}\right)$ up to the complete disappearance of the said reflexes at the temperatures exceeding $200^{\circ} \mathrm{C}$ [3]. According to [1], peak disappearance is connected with the transition from a low-temperature $\alpha-\mathrm{ZrW}_{2} \mathrm{O}_{8}\left(P{ }_{1} 3\right)$ modification to a high-temperature $\beta-\mathrm{ZrW}_{2} \mathrm{O}_{8}(\mathrm{~Pa} 3)$ modification, the transition being induced by the increase of a space group symmetry. The increase to $600^{\circ} \mathrm{C}$ lead to the appearance of weak diffraction lines that correspond to $\mathrm{WO}_{3}$ and $\mathrm{ZrO}_{2}$. A further increase of the temperature up to $750^{\circ} \mathrm{C}$ lead to the increase of the peak intensity of $\mathrm{WO}_{3}$, the appearance of $\mathrm{ZrO}_{2}$ lines and the decrease of $\mathrm{ZrW}_{2} \mathrm{O}_{8}$ reflexes.

Figure 3 demonstrates the dependence of the total intensity $(\Sigma \mathrm{I})$ of all X-ray reflexes on temperature derived from the results of XRD analysis. Below $200^{\circ} \mathrm{C}$, the total intensity goes down. Increasing the temperature from $200^{\circ} \mathrm{C}$ to $540^{\circ} \mathrm{C}$ lead to the variation of $\sum \mathrm{I}$ within the value of experimental uncertainty. The further increase of the temperature up to $750^{\circ} \mathrm{C}$ resulted in the increase of the total reflex intensity. The intersection points of approximating lines correspond to $200^{\circ} \mathrm{C}$ and $540^{\circ} \mathrm{C}$. According to the X-ray diffraction data, the drop of the total intensity was initiated by the $\alpha \rightarrow \beta$ transition and, as a consequence, by the disappearance of some reflexes. For the temperature below $540^{\circ} \mathrm{C}$ there is only the high-temperature $\beta-\mathrm{ZrW}_{2} \mathrm{O}_{8}$ modification. The increase of the total intensity up to $540^{\circ} \mathrm{C}$ can be explained by a beginning of the formation of new structures. Atoms in the zirconium tungstate structure begin to rearrange to form sublattices of tungsten and zirconium oxides. Presumably, this movement of atoms precedes the decomposition of zirconium tungstate. It is known $[1,3]$ that zirconium tungstate loses its kinetic stability and decomposes into $\mathrm{ZrO}_{2}$ and $\mathrm{WO}_{3}$ at the temperatures above $770^{\circ} \mathrm{C}$. According to XRD analysis, weak lines of $\mathrm{WO}_{3}$ and $\mathrm{ZrO}_{2}$ were observed in diffraction patterns at the temperature above $540^{\circ} \mathrm{C}$. The coefficient of thermal expansion was equal to $-9.4 \times 10^{-6} \mathrm{C}^{-1}$ for $\alpha-\mathrm{ZrW}_{2} \mathrm{O}_{8}$ and $-3.8 \times 10^{-6} \mathrm{C}^{-1}$ for $\beta-\mathrm{ZrW}_{2} \mathrm{O}_{8}$.

\section{Properties of $\mathrm{Al}-\mathrm{ZrW}_{2} \mathrm{O}_{8}$}

Materials with anomalous thermal properties may become very useful in various applications of the composites technology. Composites with a negative coefficient of thermal expansion (CTE) may become very useful in various applications: stomatology, thermal protection systems, high precision optical mirrors, fiber optic systems. Moreover, implantation of $\mathrm{ZrW}_{2} \mathrm{O}_{8}$ particles as reinforcement element into a metal matrix one can obtain the composites with high strength properties. The increase of strength properties is caused by the difference between values of thermal expansion of metal and $\mathrm{ZrW}_{2} \mathrm{O}_{8}$. Aluminum is the most easily accessed metal for studying the metal hardening due to its wide application as a construction material. The calculations showed that the internal compression stresses are generated due to the CTE difference and can reach $2 \mathrm{GPa}$ in comparison with Orowan mechanism where $\Delta \sigma \sim 20 \mathrm{MPa}$.

The structure and mechanical properties of $\mathrm{Al}-\mathrm{ZrW}_{2} \mathrm{O}_{8}$ containing $0.1,0.5,1,5$ and $10 \mathrm{wt} . \%$ of zirconium tungstate were studied. The SEM analysis showed that on the polished surface of specimens includes white particles (Fig. 5). 


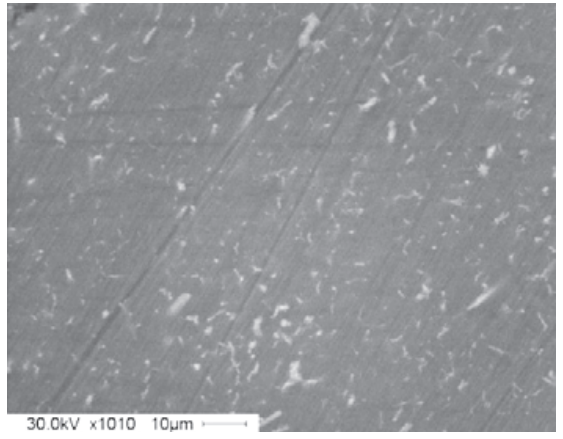

FIGURE 5. SEM pictures of $\mathrm{Al}$ with $10 \mathrm{wt} . \%$ of $\mathrm{ZrW}_{2} \mathrm{O}_{8}$

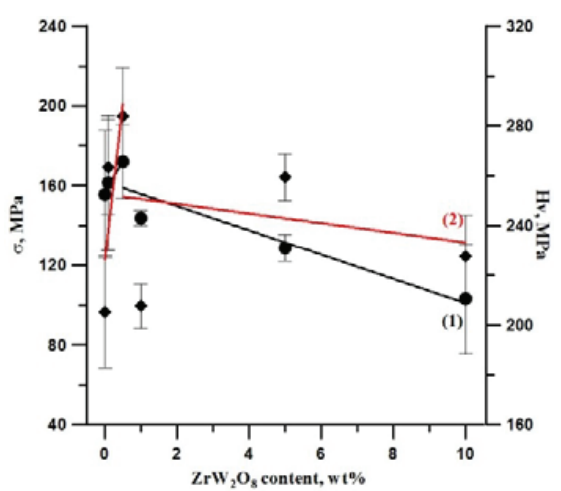

FIGURE 6. Dependence of ultimate compression strength (1) and Vickers hardness on $\mathrm{ZrW}_{2} \mathrm{O}_{8}$ content (2)

The EDAX analysis showed that these particles contain $\mathrm{Zr}, \mathrm{W}$ and $\mathrm{O}$ atoms, the correlation of the number of atoms being in a good agreement with $\mathrm{ZrW}_{2} \mathrm{O}_{8}$ stoichiometry $(\mathrm{Zr}: \mathrm{W}=1: 2)$. The average grain size of particles significantly increased with the increasing concentration of $\mathrm{ZrW}_{2} \mathrm{O}_{8}$ and did not exceed $1 \mu \mathrm{m}$ for Al with 10 wt. $\%$ of $\mathrm{ZrW}_{2} \mathrm{O}_{8}$.

From the XRD analysis it was shown that only peaks corresponding to cubic aluminum and cubic zirconium tungstate were observed. The obtained lattice parameters of aluminum and $\mathrm{ZrW}_{2} \mathrm{O}_{8}$ slightly deviate from the literature, which could be caused by microalloying of the matrix due to either the interaction during sintering process or presence of internal residual compressive stresses in the material. In the second case the compressive stresses in matrix can reach $260 \mathrm{MPa}$.

Implantation of zirconium tungstate improved the mechanical properties of aluminum. Fig. 7 shows the dependence of the ultimate compression strength and the Vickers hardness of $\mathrm{Al}-\mathrm{ZrW}_{2} \mathrm{O}_{8}$ on the content of zirconium tungstate. The highest values of hardness $\mathrm{H}_{\mathrm{V}}$ and strength $\sigma$ were achieved with the introduction of up to 0.5 wt. $\%$ of $\mathrm{ZrW}_{2} \mathrm{O}_{8}$ and were equal to $284 \mathrm{MPa}$ and $172 \mathrm{MPa}$, respectively. The further increase of $\mathrm{ZrW}_{2} \mathrm{O}_{8}$ concentration up to $10 \mathrm{wt} . \%$ deteriorates the material mechanical properties.

\section{CONCLUSION}

The formation of hydrothermally-synthesized $\mathrm{ZrW}_{2} \mathrm{O}_{8}$ proceeded in two stages: 1) transition of the crystalline $\mathrm{ZrW}_{2} \mathrm{O}_{7}(\mathrm{OH}, \mathrm{Cl})_{2} \cdot 2 \mathrm{H}_{2} \mathrm{O}$ precursor into the X-ray amorphous state with the activation energy of $\left.8 \mathrm{~kJ} / \mathrm{mol} ; 2\right)$ nucleation of $\mathrm{ZrW}_{2} \mathrm{O}_{8}$ at $350 \pm 25^{\circ} \mathrm{C}$ and the growth of nuclei up to temperature reaching $550^{\circ} \mathrm{C}(Q=1 \mathrm{~kJ} / \mathrm{mol})$. It was established that the zirconium tungstate retains its crystal structure in the range of temperatures less than $540^{\circ} \mathrm{C}$. The further increase of temperature is accompanied by the change of $\mathrm{ZrW}_{2} \mathrm{O}_{8}$ structure induced by the occurrence of $\mathrm{WO}_{3}$ and $\mathrm{ZrO}_{2}$ phases, which precedes the decomposition of zirconium tungstate into constituent oxides at the temperatures above $750^{\circ} \mathrm{C}$. The phase transition from the low-temperature $(\alpha)$ to high-temperature $(\beta)$ modification of cubic zirconium tungstate occurs at $200^{\circ} \mathrm{C}$. The coefficients of thermal expansion of zirconium tungstate powder were: $-9.6 \times 10^{-6} \mathrm{C}^{-1}$ for $\alpha-\mathrm{ZrW}_{2} \mathrm{O}_{8}$ and $-3.8 \times 10^{-6} \mathrm{C}^{-1}$ for $\beta-\mathrm{ZrW}_{2} \mathrm{O}_{8}$. It was found that the introduction of $0.5 \mathrm{wt} . \%$ of $\mathrm{ZrW}_{2} \mathrm{O}_{8}$ leads to the increase of mechanical properties of the $\mathrm{Al}-\mathrm{ZrW}_{2} \mathrm{O}_{8}\left(\mathrm{H}_{\mathrm{V}}=284 \mathrm{MPa}, \sigma=172 \mathrm{MPa}\right)$ compared with the same properties of pure aluminum.

\section{ACKNOWLEDGEMENTS}

This work was partially supported by Agreement No. 14.575.21.0040 (powders sintering part). Authors are grateful to T. Yu. Kardash from Boreskov Institute of Catalysis SB RAS for help in powders sintering (shared use center "NANOTECH").

\section{REFERENCES}

1. T. A. Mary, J. S. O. Evans, T. Vogt, and A. W Sleight, Science 272, 90 (1996).

2. S. N. Kulkov, E. S. Dedova, and A. I. Gubanov, Izv. Vyssh. Uchebn. Zaved. Fiz. 56(12/2), 151 (2013).

3. E. S. Dedova, V. S. Shadrin, A. I. Gubanov, and S. N. Kulkov, Perspekt. Mater., 5, 22 (2014). 